\title{
O ACESSO A MEDICAMENTOS E O SISTEMA INTERNACIONAL DE PROTEÇÃO À PROPRIEDADE INTELECTUAL SOB A LÓGICA DO CONTRAPODER NA SOCIEDADE EM REDE
}

\author{
THE ACCESS TO MEDICINES AND THE INTERNATIONAL SYSTEM OF \\ PROTECTION OF INTELLECTUAL PROPERTY UNDER THE LOGIC OF \\ CONTRAPOWER IN NETWORK SOCIETY
}

\section{João Pedro Seefeldt Pessoa}

Mestrando em Direito pela Universidad de León, Espanha, pelo qual é bolsista da Fundação Carolina. Mestre em Direito pela Universidade Federal de Santa Maria (UFSM). Pesquisador do Centro de Estudos e Pesquisas em Direito e Internet da Universidade Federal de Santa Maria (CEPEDI).

Rafael Santos de Oliveira

Doutor em Direito pela Universidade Federal de Santa Catarina (UFSC). Mestre em Integração Latino-Americana (Direito da Integração) pela Universidade Federal de Santa Maria (UFSM). Bacharel em Direito pela Universidade Federal de Santa Maria (UFSM). Professor Adjunto III no Departamento de Direito da Universidade Federal de Santa Maria (UFSM) e no Programa de Pós-graduação em Direito da UFSM (Mestrado).

\section{Resumo}

A lógica das redes permeia o estudo da sociedade e do poder, devido à interação entre atores sociais e a formação de redes de (contra)poder. O direito da propriedade intelectual não fica alheio, porquanto o acesso a medicamentos em determinados casos depende de mecanismos de afronta ao sistema de proteção dominante. Assim, a pesquisa tem por objetivo estudar o acesso a medicamentos no sistema internacional de proteção à propriedade intelectual sob a lógica do contrapoder exercido na sociedade em rede. Para tanto, utiliza-se o método de abordagem dedutivo, de forma que se aplica, como método de procedimento, o monográfico, bem como a técnica de pesquisa bibliográfica. Ao fim, concluiu-se que a afronta ao sistema de proteção à propriedade intelectual e a flexibilização do Acordo TRIPS é uma garantia de países menos desenvolvidos para acesso a medicamentos, alterando-se a programação e impedindo o sucesso de redes dominantes de poder.

Palavras-chave: Acesso a medicamentos. Poder em rede. Propriedade Intelectual. Sociedade em Rede. 


\begin{abstract}
The logic of networks permeates the study of society and power, due to the interaction between social actors and the formation of networks of (counter)power. The intellectual property right is not alien, since access to medicines in certain cases depends on mechanisms of affront to the dominant protection system. Thus, the research aims to study the access to medicines in the international system of protection of intellectual property under the logic of counterpower exercised in the network society. To do so, the deductive approach and the monographic procedure are used, as well as bibliographic research technique is applied. Finally, it was concluded that the affront to the system of intellectual property protection and the flexibilization of the TRIPS Agreement is a guarantee of less developed countries for access to medicines, changing programming and preventing the success of dominant networks of power.
\end{abstract}

Key-words: Access to medicines. Power on network. Intellectual Property. Network Society.

\title{
1. CONSIDERAÇÕES INICIAIS
}

A perspectiva do mundo a partir de redes não é propriamente um estudo novo, mas adquiriu força a partir de meados do século $X X$ com o desenvolvimento das tecnologias de informação e comunicação capazes de conectar as pessoas e saberes numa verdadeira mudança de paradigma. Nessa sociedade, as relações de poder são exercidas por meio de redes, que pressupõem o surgimento de redes de contrapoder com o fim de balancear a dinâmica social, inclusive no que tange às questões sociais, políticas, culturais, tecnológicas e ambientais.

Especificamente sobre o objeto do presente trabalho, percebe-se na atualidade grandes conflitos envolvendo a proteção da propriedade intelectual e o acesso a medicamentos, estando de um lado aqueles que defendem a exploração estritamente econômica do patrimônio intelectual, a partir da lucratividade das patentes de remédios; e de outro lado aqueles que atuam sob uma ótica preocupada com os aspectos sociais, as doenças negligenciadas e o fortalecimento do acesso a medicamentes por países menos desenvolvidos. Dessa forma, a presente pesquisa tenta perquirir em que medida a flexibilização de regras do sistema internacional de proteção à propriedade intelectual permite o exercício de um contrapoder para facilitar o acesso a medicamentos na sociedade em rede.

Por essa razão, o trabalho tem por objetivo geral estudar o acesso a medicamentos no sistema internacional de proteção à propriedade intelectual sob a 
lógica do contrapoder exercido na sociedade em rede. Especificamente, almeja-se analisar a mudança das relações sociais a partir do estudo das redes e visualizar as relações de poder e contrapoder na sociedade em rede; bem como estudar o atual sistema internacional de proteção à propriedade intelectual e os mecanismos de flexibilização para acesso aos medicamentos, por meio de sua ressignificação como instrumento de contrapoder.

Para realização da pesquisa, utiliza-se o método de abordagem dedutivo, porquanto se realiza uma conexão descendente, estudando-se, primeiramente, no primeiro capítulo, a perspectiva do poder nas relações sociais a partir das redes para, posteriormente, no segundo capítulo, analisar-se o poder no sistema internacional de proteção à propriedade intelectual $\mathrm{e}$, ao fim, verificar o contrapoder nos mecanismos de flexibilização desse sistema. Como método de procedimento, adota-se o monográfico, a fim de analisar o acesso a medicamentos por diversos aspectos, obtendo-se uma generalização do exercício de poder e contrapoder, sob esse panorama, na sociedade complexa atual. No que se refere às técnicas de pesquisa, emprega-se a pesquisa bibliográfica, a partir de dados primários e secundários.

\section{AS RELAÇÕES DE PODER NA TEIA DA VIDA DA SOCIEDADE EM REDE}

O século $X X$ trouxe inúmeras transformações sociais, culturais e econômicas, a partir das mudanças ocorridas graças à velocidade de se relacionar e à complexidade de ser, em especial a partir da Segunda Guerra Mundial, com a proliferação da microeletrônica. Com a profusão das tecnologias de informação e comunicação, a noção de rede foi ressignificando, adquirindo-se extrema importância nas relações intersubjetivas, vindo a inaugurar, inicialmente nos Estados Unidos, mas logo após ao redor do globo, o que Manuel Castells denominou de Era da Informação (CASTELLS, 2002).

A refundação das fronteiras entre o mundo virtual-artificial e o mundo real-vivo e a visualização das relações a partir de nós e arestas, com a horizontalização da comunicação pode ajudar a abordar essa nova arquitetura social como sociedade em rede, que, para Castells:

[...] é aquela cuja estrutura social é composta de redes ativadas por tecnologias digitais de comunicação e informação baseadas em microeletrônica. Entendo por estrutura social os acordos organizativos humanos na relação com a 
produção, o consumo, a reprodução, a experiência e o poder expressos por uma comunicação significativa codificada pela cultura. As redes digitais são globais pela sua capacidade para se autoconfigurarem de acordo com as instruções dos programadores, transcendendo os limites territoriais e institucionais através de redes de computadores ligados entre si (CASTELLS, 2016, p. 58).

Contudo, a percepção da vida a partir de redes não é exclusiva da sociedade do século XXI ou unicamente ligada às tecnologias de informação e comunicação, uma vez que "a rede é uma estrutura comum a qualquer vida; onde quer que vejamos vida, vemos redes" (CAPRA, 2002, p. 09). Nesse sentido, a rede tem sido utilizada em variados setores do conhecimento humano, de modo que vem adquirindo diversas ressignificações, a fim de explanar, abordar e questionar estruturas e processos, desde aspectos biológicos, físicos, espaciais, temporais e sociais.

Nessa linha de pensamento, deve-se ter em mente que "o novo paradigma pode ser chamado de uma visão de mundo holística que concebe o mundo como um todo integrado e não como uma coleção de partes dissociadas", posto que se "reconhece a interdependência fundamental de todos os fenômenos e o fato de que, enquanto indivíduos e sociedades, estamos todos encaixados nos processos cíclicos da natureza (CAPRA, 1996, p. 16). Ocorre que, em verdade, novos atores sociais e novos processos em redes foram criados a partir do recrudescimento das tecnologias de informação e comunicação, o que, por certo, conferiu autonomia e multidirecionalidade para proporcionar esse maior fluxo de comunicação. Nesse sentido:

[...] A sociedade em rede é pois uma sociedade global. Tal não significa, contudo, que as pessoas de todo o mundo participem nas redes. De fato, por enquanto, a maioria não o faz. Porém todo o mundo se vê afetado pelos processos que têm lugar nas redes globais desta estrutura social. As atividades básicas que configuram e controlam a vida humana em cada canto do planeta estão organizadas em redes globais: os mercados financeiros; a produção, gestão e distribuição transnacional de bens e serviços; o trabalho muito qualificado; a ciência e a tecnologia, incluindo a formação universitária; os meios de comunicação; as redes de internet de comunicação interativa multiobjeto; a arte, a cultura, os espetáculos e os desportos; as instituições internacionais que gerem a economia global $e$ as relações intergovernamentais; a religião; a economia criminal; e as ONG transnacionais e os movimentos sociais que fazem valer os direitos e valores de uma nova sociedade civil global. (CASTELLS, 2016, p. 59).

Nesse diapasão, emprestando-se conceitos da teoria dos grafos, uma rede pode ser entendida como um grupo relevante de nós conectados por arestas, em uma 
distribuição espacial. Com a influência mútua de determinados nós a outros nós dessa rede, torna-se possível visualizar significações diferentes, ainda que todos os nós sejam indispensáveis ao funcionamento da rede (CASTELLS, 2016, p. 53). Quando determinado nó não mais é necessário, a própria rede intenta se reconfigurar para eliminar antigos centros e acrescentar outros, de modo que a rede é a unidade e o nó é um componente de um organismo como um todo (CASTELLS, 2016, p. 53).

Castells esclarece que o sucesso das redes reside na possibilidade de flexibilidade, adaptabilidade e capacidade de sobrevivência destas, considerando que as redes podem alterar tendo em vista mudanças de espaço, encontrar novas ligações, mesmo existindo pontos de bloqueio e alteração de componentes, bem como expandirse ou reduzir seu tamanho sem grandes alterações (CASTELLS, 2016, p. 57). Não obstante, é por não haver um centro único que a rede pode se conformar a partir de um sem número de possibilidades, inclusive resistir a ataques aos nós e aos códigos transportados, porque diferentes núcleos podem direcionar a informação. (CASTELLS, 2016, p. 57).

Em outras palavras:

[...] as redes são estruturas complexas de comunicação estabelecidas em torno de um conjunto de objetivos que garantem, ao mesmo tempo, unidade de propósitos e flexibilidade na sua execução graças à sua capacidade para adaptar o contexto operativo. As redes estão programadas e ao mesmo tempo são autoconfiguráveis. Nas redes sociais e organizativas, os objetivos e procedimentos operativos são programados pelos atores sociais. A sua estrutura evolui de acordo com a capacidade da rede para se autoconfigurar numa procura interminável de configurações de rede mais eficientes. (CASTELLS, 2016, p. 54)

Cumpre destacar não haver, contudo, apenas uma rede existente, mas, sim, uma rede de redes, podendo uma rede interagir com vários outras tantas, em formas de cooperação (comunicar entre si) ou competição com outra. Capra (1996, p. 35), sobre a ecologia da teia da vida, a partir de uma nova visão dos fenômenos, diz que "desde que os sistemas vivos, em todos os níveis, são redes, devemos visualizar a teia da vida como sistemas vivos (redes) interagindo à maneira de rede com outros sistemas (redes) [...]", sendo que "teia da vida consiste em redes dentro de redes, em cada escala, sob estreito e minucioso exame, os nodos da rede se revelam como redes menores".

No que toca às relações sociais, as estruturas comunicativas parecem estabelecer as redes, à medida que as arestas dos grafos podem ser compreendidas 
como fluxos de informações que percorre por diferentes atores sociais. Essa troca de informações entre os atores sociais reprogramam e configuram a rede a todo momento em função de determinados critérios, que Manuel Castells denomina como protocolos de comunicação (2016, p. 53).

Em outras palavras, a disposição da rede, nas relações sociais, regenera-se a partir de cada comunicação realizada, tendo em vista que cada fluxo de informação percorrido compreende novas significações e reações nos atores sociais. Isso quer dizer que, por meio dos protocolos de comunicação, valores, crenças e visões do mundo são reintroduzidos, reforçados e retroalimentados a todo instante na rede, sendo que um nó pode acabar por se conectar ou se desconectar de determinadas arestas e outros nós graças a um sentimento de pertencimento, isto é, atores ou organizações sociais podem comunicar-se ou distanciar-se entre si a depender do "contexto comum de significados" (CAPRA, 2002, p. 86).

É possível, então, referir que essa perspectiva de visualização dos fenômenos da vida a partir de redes representa uma ressignificação na visão da sociedade, diante do rompimento com o panorama moderno predominante de organização burocrática, de disposição hierárquica e de verticalização dos processos, de forma que "a mudança de paradigma inclui, dessa maneira, uma mudança na organização social, uma mudança de hierarquias para redes" (CAPRA, 2002, p. 19). Cabe abraçar, assim, a ideia de complexidade de um mundo multicultural, donde tudo e todos terminam por sofrer influência direta ou indireta de tudo e todos, não havendo o que se falar em discursos, estudos e conceitos sedizentes ideologicamente neutros.

Isso não quer dizer que, nessa nova dinâmica, por exemplo, um determinado nó não se justaponha sobre outro ou que uma determinada rede não se sobreponha sobre outra, haja vista que essa arquitetura social não fica imune às relações de poder, pois, em apertada síntese, poder é "a capacidade relacional que permite ao ator social influenciar de forma assimétrica as decisões de outro(s) ator(es) social(is) no sentido de favorecimento da vontade, interesses e valores do ator com poder", sendo exercido "por meios de coerção e/ou pela construção de significados base dos discursos através dos quais os atores sociais guiam a sua ação". (CASTELLS, 2016, p. 41).

Nesse contexto peculiar, cabe mencionar que as fontes de poder social, isto é, sobre as relações sociais, não foram alteradas ao longo dos anos, uma vez que o poder ainda é originário de dispositivos, que, na concepção de Foucault, são 
"discursos, instituições, organizações arquitetônicas, decisões regulamentares, leis, medidas administrativas, enunciados científicos, proposições filosóficas, morais, filantrópicas" que guardam uma função dominante para determinar a forma condicionante na sociedade (FOUCAULT, 2004, p. 138). No entanto, a revolução consiste na nova dinâmica das relações de poder que, hodiernamente, perpetuam-se numa conexão entre o global e o local, de forma organizada em rede, já que, consoante Capra (1996, p. 19), “a estrutura ideal para exercer esse tipo de poder [como influência de outros] não é a hierarquia, mas a rede".

Por outro lado, a análise supracitada admite o aparecimento de redes de contrapoder, porquanto os protocolos de comunicação entre nós e redes de poder podem gerar resistência por outras redes também de poder, no caso, contrapoder, a depender do referencial de visualização; ou, ainda, as redes de poder que pretendem a diminuição ou a exclusão de outra rede podem sofrer certa retaliação por aquelas redes que desejam participar dessa dinâmica ou que, no mínimo, querem contestar essa lógica excludente (CASTELLS, 2016, p. 85-86). Dessa maneira: sejam as relações de poder, sejam as relações de contrapoder, ambas configuram redes e se submetem às análises mencionadas.

Nas palavras de Castells:

\begin{abstract}
Os processos de construção de poder devem olhar-se a partir de duas perspectivas: por um lado, podem aplicar a dominação existente ou adquirir posições estruturais de dominação; por outro lado, também há processos de resistência ao poder, em nome de interesses, valores e projetos excluídos ou sub-representados nos programas e composição das redes. Analiticamente, ambos os processos configuram em última instância as estruturas de poder mediante a sua interação. São diferentes, embora atuem sob a mesma lógica. Isto quer dizer que a resistência ao poder efetua-se mediante os dois mecanismos que constituem o poder na sociedade em rede: os programas das redes e a ligação entre elas. (CASTELLS, 2016, p. 86).
\end{abstract}

Nesse sentido, a partir da introdução de novos ou destruição de determinados códigos nos programas das redes por atores sociais ou organizações sociais, é possível gerar novos protocolos de comunicação e reprogramar a rede, para além da forma e da expansão, mas também no que tange ao conteúdo da rede (CASTELLS, 2016, p. 88). Castells finaliza sobre as redes de contrapoder:

Na sociedade em rede o poder está redefinido, mas não desapareceu. Tal como não desapareceram os conflitos sociais. A dominação e a resistência à dominação mudam de caráter segundo a estrutura social específica em que se originam e que modificam com a sua ação. $O$ poder governa, o contrapoder 
combate. As redes processam os seus programas contraditórios enquanto as pessoas tentam encontrar sentido para a fonte dos seus medos e das suas esperanças. (CASTELLS, 2016, p. 89)

Assim, enquanto a conexão entre as redes é, na sociedade em rede, uma das formas de exercício do poder, a resistência a tais programações e o aniquilamento de determinadas ligações para defesa de interesses adversos aos protocolos dominantes podem ser compreendidos como exercício de contrapoder. Ambas as relações de poder podem ser visualizadas a partir da lógica de redes, nós e arestas, embora o poder tenda a ser global e o contrapoder ser local. Numa análise mais exemplificativa de como funcionam essas arquiteturas de poder, especialmente de programas alterativos e valores substitutivos, cita-se atores, movimentos e conexões sociais anticapitalistas, alterglobalistas, antifundamentalistas, ambientalistas, dentre outros, sendo que, nos próximos capítulos, apresentar-se-á essa lógica no que tange ao sistema de proteção à propriedade intelectual.

\section{DO PODER DO SISTEMA INTERNACIONAL DE PROTEÇÃO À PROPRIEDADE INTELECTUAL}

A evolução do sistema internacional de propriedade intelectual pode ser descrita a partir da análise de quatro principais marcos legais: a) Convenção da União de Paris, de 1883; b) a Convenção da União de Berna, de 1886); c) o Acordo sobre os Aspectos dos Direitos de Propriedade Intelectual Relacionados ao Comércio (Acordo TRIPS), de 1994; e d) os tratados de livre-comércio bilaterais e multilaterais firmados entre diferentes países. Esses paradigmas normativos foram influenciados pelo - e de certa forma também influenciaram o - desenvolvimento econômico e tecnológico dos países ao longo dos anos, alterando-se, assim, a dinâmica do comércio internacional.

Em 1883, alguns países se reuniram numa primeira tentativa de harmonização e construção de um sistema internacional de propriedade intelectual, dentre eles o Brasil, no que ficou conhecida como Convenção da União de Paris (CUP) (WIPO, $2019 \mathrm{~b}, \mathrm{~s} / \mathrm{p}$ ). Esse acordo internacional relativo à propriedade intelectual continua em vigor até os dias de hoje, embora tenha sofrido revisões periódicas, a saber Bruxelas (1900), Washington (1911), Haia (1925), Londres (1934), Lisboa (1958) e Estocolmo (1967), sendo adotado por, pelo menos, 177 (cento e setenta e sete) países (WIPO, 
2019b, s/p).

Aconteceu que a CUP não foi ambiciosa, porque:

\begin{abstract}
Não havia pressão pelo estabelecimento de normas multilaterais para a proteção da propriedade industrial: o que predominava era o desejo de diminuir e gerenciar os conflitos entre os países no que tange às diferenças entre seus regimes de propriedade intelectual. A Convenção reconhecia o direito dos países membros de adotar o regime de proteção aos direitos de propriedade intelectual que mais thes parecesse adequado. Assim sendo, no contexto do setor farmacêutico, todos os Estados signatários da Convenção tinham liberdade para decidir se patentes seriam ou não concedidas para medicamentos (ROSINA, 2007, p. 8).
\end{abstract}

Desse tratado, importante mencionar três características: tratamento igual para nacional e estrangeiro, direito de prioridade e, independência das patentes. $\mathrm{O}$ princípio do tratamento igual para nacionais e estrangeiros, previsto no art. $2^{\circ}$, da CUP, aborda que não haverá distinções entre inventores dos países signatários do acordo, de maneira que nenhum país pode conceder tratamento preferencial ou discriminatório em favor de um nacional e em desfavor de um estrangeiro, devendo as mesmas vantagens previstas na legislação de cada país serem garantidas aos nacionais de todos os países acordantes (BRASIL, 1975, s/p).

Por sua vez, o direito de prioridade, trazido pelo art. $4^{\circ}$, da CUP, estabelece que o requerente de uma patente em determinado país possui o direito de prioridade sobre aquela invenção, pelo prazo de 12 (doze) meses a contar da data de apresentação do primeiro pedido, para depositar igual pedido em diferente país signatário (BRASIL, 1975, s/p). Isso quer dizer que, havendo sido apresentado um pedido em determinado país, o requerente poderá estender a proteção patentária aos demais países, desde que o faça no prazo legal, ainda que haja requerimento posterior de outro inventor no mesmo sentido.

E o princípio da independência das partes, previsto no art. $4^{\circ}$, bis, da CUP, alerta que o pedido de patente concedido em determinado país signatário não guarda relação com a patente concedida em outro país, devendo o inventor se sujeitar às determinações legais e regulamentares de cada local para melhor aproveitamento da patente, especialmente no que tange à caducidade e causas de nulidade (BRASIL, 1975, s/p). Assim, não há que se falar em patente internacional ou global, porquanto está é considerada um título de propriedade de âmbito nacional.

Por fim, rememora-se que a CUP também não unificou no âmbito internacional as regras relativas à propriedade industrial, tendo em vista que "apenas estabeleceu 
um mecanismo de compatibilização que permitia a coexistência da diversidade nacional sem prejuízo de interesses na esfera internacional” (ROSINA, 2007, p. 07). Dessa forma, "cada país ficou livre para estabelecer suas políticas internas de proteção à propriedade industrial, respeitados os princípios acima citados" (ROSINA, 2007, p. $07)$.

Em 1886, noutra perspectiva de direitos de propriedade intelectual, os países se reuniram para proteger as obras literárias e artísticas, inclusive científicas, no que ficou, por seu turno, conhecida como Convenção Única de Berna (WIPO, 2019a, s/p). De igual forma, a CUB continua em vigor até os dias de hoje, sendo revista em Roma (1928), Bruxelas (1948), Estocolmo (1967) e Paris (1971), e emendada em 1979, abrigando, pelo menos, 175 (cento e setenta e cinco) países (WIPO, 2019a, s/p).

Daí que, em 1893, houve a fusão das sedes e escritórios da CUP e CUB para criação do Escritório Unificado Internacional para a Proteção da Propriedade Intelectual (BIRPI), que, em 1970, deu origem à Organização Mundial da Propriedade Intelectual (OMPI) (WIPO, 2019c, s/p). Esta última é uma das agências da Organização das Nações Unidas (ONU), com o fito de administrar os tratados internacionais de proteção intelectual, embora tenha perdido um pouco de espaço com a criação da Organização Mundial do Comércio (OMC), também vinculada à ONU.

A partir da Segunda Guerra Mundial, porém, vê-se o recrudescimento de um novo sistema econômico global, inclusive alinhado para produção, distribuição, valoração e consumo de produtos e serviços em rede. Nesse ínterim, surgiram novas organizações internacionais, mediante acordos multilaterais, para mediar as relações comerciais, como, por exemplo, o Fundo Monetário Internacional (FMI) e o Banco Mundial (BM) (PRONER, 2007, p. 22)

Para fins de redução de tarifas alfandegárias e minimização de práticas ilegais, irregulares e desleais de comércio internacional, diversos países se reuniram para uma série de rodadas de negociações comerciais multilaterais e concessões mútuas, no que ficou conhecido como Acordo Geral sobre Tarifas e Comércio (na sigla GATT), até que fosse criada uma organização internacional para o comércio (PRONER, 2007, p. 24). Os vinte e dois membros fundadores foram África do Sul, Austrália, Bélgica, Brasil, Canadá, Ceilão, Chile, China, Cuba, Checoslováquia, Estados Unidos, França, Holanda, Índia, Líbano, Luxemburgo, Nova Zelândia, Noruega, Paquistão, Reino Unido, Rodésia do Sul e Síria (WTO, 2019a). 
Na década de 70 e 80 , é possível perceber algumas mudanças no cenário econômico mundial, surgindo dois tipos de posicionamentos, um "entendimento de que a propriedade intelectual constitui um bem público universal, necessário para promover o desenvolvimento econômico e social da humanidade, posição defendida pelos países em desenvolvimento" e, de outro lado, "a posição que considera a propriedade intelectual um bem privado, objeto de necessária proteção como qualquer outra propriedade, posição dos países desenvolvidos" (PRONER, 2007, p. 25). Ainda, notase diversos outros fenômenos que alteraram a economia mundial, como unificação dos mercados financeiros, mobilidade única de capital e associações entre transnacionais, num processo de globalização (CASTELLS, 2016, p. 59).

Diante desse cenário, mas principalmente cedendo à pressão de interesses de indústrias de cibertecnologia e microeletrônica, produtos químicos, farmacêuticos e de biotecnologia, os Estados Unidos trouxeram o tema da propriedade intelectual na Rodada de Uruguai (POGGE, 2008, p. 127). Assim, em 1986, teve início essa nova rodada de negociações, que, encerrada em Marrocos, em 1994, culminou com a criação da Organização Mundial do Comércio e com a adesão de variados acordos multilaterais, citando-se, dentre eles, o Acordo TRIPS (WTO, 2019c).

O Acordo sobre Aspectos dos Direitos de Propriedade Intelectual Relacionados ao Comércio, ou comumente denominado Acordo TRIPS, é, hoje, o principal marco normativo de regulação do sistema internacional de propriedade intelectual, devendo ser compulsoriamente internalizado por cada um dos países membros da OMC (WTO, 2019c). Cumpre destacar que, por sua excelência, o acordo estabelece normativas mais rígidas, à esteira daquilo praticado pelos países desenvolvidos, e não permite que cada país adote um sistema diferenciado que favoreça o próprio desenvolvimento tecnológico, mas, sim, regional e global, atendendo aos interesses mundiais.

O Acordo possui regras de padrões mínimos a serem adotados pelos membros signatários, embora cada país possa adaptar a legislação interna em determinados pontos flexíveis (WTO, 2019c). Além disso, o Acordo TRIPS prevê mecanismos de aplicação, que podem ser copiados pelos países signatários, a fim de cada vez mais uniformizar o tratamento dos direitos de propriedade intelectual (WTO, 2019c). O tratado prevê, ainda, um sistema internacional de solução de controvérsias, podendo dispor penalidades para membros que não cumprirem as regras determinadas.

Nesse sentido: 
De fato, ao "refinar" o modelo anteriormente existente de proteção à propriedade intelectual, a OMC não só estabeleceu um novo patamar de proteção normativa, mas também criou instrumento que garantiram sua efetiva aplicação e seu cumprimento, traduzidos na capacidade da organização de condenar, por meio de um sistema de solução de controvérsias eficaz, aqueles países que não se adequassem ao novo regime. O resultado: regras mais severas e uma organização internacional que, pela primeira vez na história, possui capacidade e legitimidade para garantir o cumprimento de suas normas (ROSINA, 2011, p. 20).

Para tanto, o tratado trouxe, nos artigos 65 e 66, prazos para que cada país membro da OMC adequasse a legislação interna sobre propriedade intelectual de acordo com os padrões mínimos estabelecidos, variando conforme o nível de desenvolvimento do Estado (BRASIL, 1994, s/p). Desse modo, países desenvolvidos possuíam o prazo de 01 (um) ano para adaptação, isto é, até 1996; enquanto que países em desenvolvimento ou menos desenvolvidos tiveram 05 (cinco) anos (até 2000) e 11 (onze) anos (até 2006), respectivamente, para reformular a legislação (BRASIL, 1994, s/p).

Importante considerar que, até então, certos países entendiam pela impossibilidade de monopólios sobre fármacos e alimentos, uma vez que tal patenteamento afetaria, sobremaneira, a sobrevivência humana por causa da lógica mercantilista. Contudo, o Acordo TRIPS, no art. 27.1, primeira parte, trouxe que é patenteável qualquer invenção de produto ou de processo, em todos os setores tecnológicos, razão pela qual se fez necessária a alteração de diversas legislações internas ao redor do mundo (BRASIL, 1994, s/p).

O Brasil, mesmo possuindo o prazo de adaptação de até 05 (cinco) anos, reformulou completamente a legislação interna em 1996, promulgando a Lei n. ${ }^{\circ}$ 9.279/96, que regula direitos e obrigações relativos à propriedade industrial, cedendo à pressão dos Estados Unidos e dos outros países desenvolvidos (BRASIL, 1996, s/p). Outros países, como Argentina, Costa Rica, Honduras, Paraguai e Uruguai, utilizaram parcialmente o prazo de transição, mas se utilizaram do instituto da pipeline, permitindo uma proteção retroativa a produtos farmacêuticos patenteados em outros países, mas ainda não comercializados localmente (CHAVES et al, 2007, p. 260).

Observa-se, portanto, um sistema internacional de proteção à propriedade intelectual, no âmbito da Organização Mundial do Comércio, especialmente regulado pelo Acordo TRIPS e outros tratados regionais. Desse modo, as patentes, inclusive de medicamentos, estão sujeitas à lógica comercial mundial e reféns do modelo 
econômico desenvolvido que favorece países desenvolvidos e grandes corporações farmacêuticas e de pesquisa e desenvolvimento. A afronta a esse sistema pode gerar graves consequências comerciais aos países menos desenvolvidos, que podem sofrer embargos econômicos e outras sanções, inclusive pela OMC, caso não contribuam com a dialética mercantilista.

\section{DO CONTRAPODER AO SISTEMA INTERNACIONAL DE PROTEÇÃO À PROPRIEDADE INTELECTUAL E O ACESSO A MEDICAMENTOS}

Primeiramente, é de se notar a desigualdade socioeconômica radical que aflige o mundo, que, para além de um desnivelamento entre as próprias nações em desenvolvidas, em desenvolvimento e subdesenvolvidas, evidencia uma disparidade entre os próprios nacionais, já que, por exemplo, em relatório produzido pela Oxfam International, em 2017, 42 pessoas possuíam a mesma riqueza dos 3,7 bilhões mais pobres do mundo e, no Brasil, cinco ultrarricos detinham a riqueza igual à da metade da população brasileira (MENA, 2018, s/n). Porém, essa desigualdade não afeta somente o acesso dos mais pobres a bens e serviços consumidos pelos mais ricos, mas impede o gozo de necessidades básicas e direitos fundamentais da maioria da população mundial.

A pobreza perpétua vivenciada por mais da metade da humanidade apresenta sérios perigos de saúde e de vida, porquanto tais pessoas estão mais expostas a riscos ambientais, causados por água contaminada, sujeira, poluição, agentes patogênicos; estão mais expostas a perigos sociais, como crimes, trabalhos insalubres e doenças contagiosas; não possuem reservas financeiras ou condições para acessar direitos e mecanismos complementares, como melhor tratamento médico, dentre outras precariedades (POGGE, 2008, p. 124). Dessa forma, as pessoas mais pobres estão expostas a maior carga global de doenças (CGD), o que exige dos governos ações positivas para concretizar o direito à saúde.

Por outro lado, o progresso da medicina para desenvolvimento de medicamentos e tratamentos de saúde depende, essencialmente, de financiamento governamental e da receita de vendas, o que conduz a saúde à lógica mercantilista, que depende de capital para custeio da produção e para distribuição de lucros (POGGE, 2008, p. 125). Assim, o custo da pesquisa e desenvolvimento (P\&D) de um novo medicamento é elevado, de modo que, para barrar concorrentes, aumentar o 
preço de venda, recuperar os gastos em pesquisa e afastar o preço do custo marginal, a solução encontrada por essas grandes corporações é o sistema de proteção da propriedade intelectual, por meio do monopólio das patentes. Dessa forma, enquanto durar o monopólio da patente, o desenvolvimento, a produção e a venda desse objeto é proibida aos demais, salvo autorização do detentor da patente.

Thomas Pogge (2008, p. 128-130) aponta sete inconvenientes do sistema atual de proteção à propriedade intelectual. Em primeiro lugar, refere-se o preço alto imposto aos medicamentos, de caráter monopolista de maximização dos lucros, verificado, em larga medida, pela curva de demanda dos ricos, de forma que o acesso aos medicamentos pelos mais pobres depende da caridade dos ricos (POGGE, 2008, p. 128). Segundamente, cita-se a negligência em relação às doenças concentradas nas populações pobres, visto que, embora disseminadas e graves, não se tornam objetivos lucrativos para a indústria farmacêutica, tendo em vista as parcas condições financeiras dessas comunidades, num problema conhecido como 10/90 em que somente $10 \%$ de todas as pesquisas farmacêuticas estão voltadas para doenças que respondem por 90\% da CGD (POGGE, 2008, p. 128).

Por terceiro, verifica-se a preferência pelo alívio aos sintomas, haja vista que tais medicamentos são mais lucrativos porque não curam totalmente o usuário, mas também não o deixam morrer, transformando-se os pacientes em consumidores (POGGE, 2008, p. 128). Em quarto lugar, nota-se um suposto desperdício, porquanto os inventores precisam patentear, monitorar e defender os inventos em várias jurisdições, já que, como referido, trata-se de um título de propriedade nacional (POGGE, 2008, p. 129).

Por quinto, menciona-se a ocorrência de falsificação de medicamentos, que podem acabar por reduzir os lucros do inventor e enfraquecer os incentivos para pesquisa e desenvolvimento, além de, quando a falsificação não é totalmente equivalente e, sim, com algo diluído, adulterado, ou até tóxico, pode colocar em risco a saúde do usuário (POGGE, 2008, p. 129). Em sexto, considerando a lógica consumerista, visualiza-se um marketing excessivo sobre tais produtos, tanto direcionado à persuasão de consumidores para tomarem remédios que nem sempre precisam ou para doenças que realmente não têm, quanto dirigido a exercer influência sobre o receituário dos médicos, em grandes conferências e eventos (POGGE, 2008, p. 129). 
Por fim, ressalta-se o problema da última milha, porquanto a indústria farmacêutica recebe incentivo para apenas produzir e vender o medicamento, faltando infraestrutura para distribuir e supervisionar conscientemente o consumo adequado dos produtos pelos pacientes, de forma que, sendo vendido o remédio, a competência da indústria já se acabaria (POGGE, 2008, p. 129). Além disso, não é de se espantar que, nesse espaço em que a indústria está inserida, é preciso que a doença-alvo também prospere e se dissemine para manter ou aumentar a demanda no mercado pelo remédio (POGGE, 2008, p. 129).

E, pede-se vênia para incluir, ainda, a questão do acesso e da exploração do patrimônio genético e dos conhecimentos tradicionais de países com grande sociobiodiversidade, a partir do conflito ideológico e dos propósitos pensados, se fornecedores mundiais de commodities ou mecanismo de emancipação social para a população local (ARAÚJO, 2013, p. 271). Shiva menciona que o Acordo TRIPS "baseia-se em um conceito de inovação extremamente restrito que, por definição, tende a favorecer as corporações transnacionais em detrimento dos camponeses e povos das florestas do Terceiro Mundo em particular", de modo que os direitos de propriedade intelectual, nesse sistema, "são reconhecidos apenas quando o conhecimento e a inovação geram lucro e não quando satisfazem necessidades sociais" (SHIVA, 2002, p. 31), o que exige um posicionamento desses países alvo de exploração.

Diante desse panorama, dois grandes marcos normativos ajudam os países em desenvolvimento e menos desenvolvidos nessa postura contraproducente: Convenção da Diversidade Biológica e Declaração de Doha. Durante a ECO-92, propôs-se a assinatura da Convenção sobre a Diversidade Biológica - CDB, acordo internacional multicultural com enfoque na proteção da biodiversidade, na sustentabilidade dos recursos e na repartição equitativa dos benefícios advindos da exploração do patrimônio genético, que também desemboca na criação de patentes e desenvolvimento de medicinas, sendo o documento assinado pelo Brasil e internalizado através do Decreto $n .^{\circ} 2.519 / 98$ (BRASIL, 1998). Ocorre que o Acordo TRIPS, encabeçado pelos países do Norte Social e abordado no âmbito do comércio mundial, acaba por prevalecer e proteger sobremaneira o monopólio das patentes (BRASIL, 1994).

A Declaração de Doha, oriunda de negociações multilaterais no âmbito da OMC, trouxe a questão do acesso a medicamentos na agenda do comércio 
internacional em 2001, durante a IV Conferência Ministerial, no Qatar (BRASIL, 2019, $\mathrm{s} / \mathrm{p}$ ). Embora não tenha alterado o Acordo TRIPS em nada, constitui-se, em verdade, de um instrumento político em favor dos países em desenvolvimento e menos desenvolvidos para justificativa de implementação das flexibilidades previstas nos acordos de propriedade intelectual (WTO, 2001b, s/p). Ademais, reconheceu-se, no parágrafo $6^{\circ}$, a necessidade de solucionar o problema dos países que não possuem tecnologia local para garantir o desenvolvimento das licenças compulsórias, permitindo, a partir de uma emenda ao Acordo TRIPS, a importação de medicamentos de outros países que já tenham "quebrado" determinada patente (WTO, 2001b, s/p).

Durantes tais negociações realizadas ao longo dos anos, é possível perceber, nitidamente, a existência de, pelo menos, dois grupos: um formado por União Europeia, Estados Unidos, Austrália e Japão reivindicando o acesso a mercados globais e prevalência dos acordos econômicos; e outro formado por países como Brasil, Índia e outros da Comunidade de Países de Língua Portuguesa, clamando pela maior participação das nações menos desenvolvidas no comércio internacional a partir de mecanismos para tanto e pela proteção da saúde pública com o favorecimento de acesso a medicamentos (GALITO, 2011, p. 07-08). Não obstante a rodada ainda não tenha sido finalizada, demonstrou importante força por parte da ligação do Sul-Social e aproximação com o Norte-Social, por meio da intermediação de Portugal (COMUNIDADE DOS PAÍSES DE LÍNGUA PORTUGUESA, 2002).

Nesse ínterim, citam-se alguns mecanismos de flexibilização das regras do Acordo TRIPS de proteção da propriedade intelectual. A exaustão internacional de direitos ou importação paralela, prevista no art. $6^{\circ}$ do Acordo TRIPS, permite que um país importe um produto patenteado de outra nação, caso esse objeto já esteja no mercado do país estrangeiro colocado ou consentido pelo detentor do invento (BRASIL, 1994). Trata-se apenas de uma relação negocial entre países de exportaçãoimportação, já que os direitos do inventor já estão exauridos pela recompensa da patente no país que vende o produto. Dessa forma, um país pode importar medicamentos com um preço menor e praticar determinado preço em seu território, dificultando que a indústria farmacêutica faça segmentação de mercado e pratique diferentes preços.

O uso experimental e a exceção Bolar são permitidos pelo art. 30 do Acordo TRIPS, sendo limitadores dos direitos conferidos pelas patentes em determinados 
países (BRASIL, 1994). O uso experimental autoriza a exploração científica para fins de pesquisa acerca do produto patenteado antes do término do prazo de concessão do monopólio, a partir de informações eventualmente reveladas ou conseguidas do inventor. A exceção Bolar, por sua vez, como se fosse uma espécie de uso experimental, é um mecanismo que admite a realização de testes científicos em objetos patenteados antecipadamente ao término do prazo do monopólio para fins de aprovação e registro em agências reguladoras, possibilitando, por exemplo, que um medicamente genérico seja disponibilizado imediatamente após a expiração da concessão.

A licença compulsória - talvez o mecanismo mais poderoso e polêmico em razão do enfraquecimento da relação entre país e indústria farmacêutica e possíveis sanções e embargos comerciais - é uma autorização governamental para exploração de um produto patenteado por terceiros, que ocorre sem o consentimento do titular do monopólio, na forma do art. 31, do Acordo TRIPS (BRASIL, 1994). Dessa maneira, a licença compulsória poderá ser decretada em circunstâncias excepcionais, como, por exemplo, no caso brasileiro, de acordo com a Lei n. ${ }^{\circ}$ 9.279/96, por insuficiência de exploração, exercício abusivo, abuso do poder econômico, dependência de patentes, interesse público ou situação emergencial (BRASIL, 1996).

Diversos países já praticaram, pelo menos uma única vez, o regime de licença compulsória, ou, então, utilizaram-se desse mecanismo para reduzir o preço de determinados remédios. Na década de 60 e 70, Estados Unidos produziu tetraciclina e meprobamato para fins militares; na década de 80 , decretou a quebra da patente da insulina; entre 80 e 90, firmou seis licenças compulsórias para evitar monopólio de mercado devido a fusão de grandes indústrias (LOVE, 2007, p. 03-06). Entre a década de 60 e 90, o Canadá emitiu mais de seiscentas licenças compulsórias, permitindo uma grande produção de farmacêuticos, o que veio a parar com as futuras negociações no âmbito do NAFTA (LOVE, 2007, p. 06-07). O Brasil, por sua vez, desde a Lei n. ${ }^{\circ}$ 9.313/96, que dispõe sobre a gratuidade do tratamento da AIDS e combate ao HIV, enfrentou dificuldades no pagamento dos royalties sobre medicamentos antirretrovirais, vindo, por meio do Decreto n. ${ }^{\circ} 6.108 / 07$, promulgar o licenciamento compulsório do remédio efavirenz (LOVE, 2007, p. 14-15).

Por outro lado, a patente de segundo uso, embora não prevista no Acordo TRIPS, é a possibilidade de se patentear uma mesma substância considerando outra aplicação medicinal, ou outro grupo de paciente, ou outro efeito funcional, ou outra 
administração do medicamento, ou outra fórmula semelhante, estendendo-se o monopólio da patente por mais um prazo para exploração do inventor (MARINHO, 2005 apud PINTO, 2012, p. 194). Em verdade, o tema gera bastantes controvérsias, de modo que é a proibição do segundo uso um mecanismo de combate à dominação econômica de grandes indústrias farmacêuticas.

Argumenta-se que o segundo uso impediria a produção e delongaria o fornecimento de medicamentos genéricos no mercado, em virtude do maior prazo concedido, como se fosse um novo produto patenteado, bem como aumentaria os gastos governamentais por anos para colocação de determinados medicamentos na rede pública (PINTO, 2012, p. 195-196). Ainda, debate-se que, sendo a inovação um dos aspectos das leis de propriedade intelectual, o segundo uso é trivial, porquanto outros inventores poderiam facilmente descobri-lo quando do caimento em público da primeira patente e, como não o podem fazê-lo, ocorreria um desincentivo a outras e novas empresas de entrarem no mercado, prejudicando a livre concorrência (PINTO, 2012, p. 195-196).

Em importante julgado, a Segunda Turma Especializada do Tribunal Regional Federal da $2^{\mathrm{a}}$ Região, em litígio proposto pela indústria farmacêutica Eli Lilly \& Company, envolvendo a rejeição de uma patente de segundo uso pelo Instituto Nacional de Propriedade Industrial, órgão governamental brasileiro responsável pelo registro de patentes, entendeu que "a concessão de um novo monopólio - para um segundo uso de substâncias já conhecidas - prolongaria indefinidamente os direitos privados do titular da patente sobre uma matéria que não apresenta os requisitos, internacionalmente aceitos", sendo que, ainda, "em contrapartida, reduziria o direito público de acesso aos novos conhecimentos pela sociedade brasileira, e impediria que pesquisadores nacionais desenvolvessem novas formulações e novos medicamentos" (BRASIL, 2009).

Por fim, a participação do setor de saúde no processo de análise dos pedidos de patentes de produtos e processos farmacêuticos pode ser considerada uma flexibilização implícita no art. $8^{\circ}$ do Acordo TRIPS, permitindo aos países membros da OMC "adotarem medidas necessárias para proteger a saúde pública e nutrição e para promover o interesse público em setores de vital importância para o desenvolvimento socioeconômico e tecnológico, desde que compatíveis com o disposto no Acordo" (BRASIL, 1994). Nesse contexto, o Brasil, por exemplo, por meio de uma emenda à Lei 
n. ${ }^{\circ}$ 9.279/96, incluiu o art. 229-C, determinando que a concessão de patentes para produtos e processos farmacêuticos dependerá da prévia anuência da Agência Nacional de Vigilância Sanitária - ANVISA, a fim de evitar a emissão de monopólios injustificáveis e proteger o interesse público de acesso a medicamentos (BRASIL, 1996).

\section{CONSIDERAÇÕES FINAIS}

Desde meados do século passado, é notável a existência de grandes conflitos envolvendo a temática do acesso a medicamentos protegidos por direitos de propriedade intelectual, quando, de um lado, coloca-se a exploração econômica do monopólio de patentes por países desenvolvidos; e, de outro lado, põe-se a perspectiva social preocupada com o direito fundamental à saúde e a disponibilização de medicinas, especialmente a populações mais pobres de países em desenvolvimento ou menos desenvolvidos. Essa controvérsia é objeto de estudo do direito à propriedade intelectual e, por consequência, da presente pesquisa, a qual, por sua, vez, adquire outro contorno a partir da visualização do poder na sociedade em rede. Desse modo, o presente trabalho procurou debater em que medida a flexibilização de regras do sistema internacional de proteção à propriedade intelectual permite o exercício de um contrapoder para facilitar o acesso a medicamentos na sociedade em rede.

Quando do primeiro capítulo, observou-se que, após a Segunda Guerra Mundial, ocorreu uma transformação de paradigma de noção da vida, em virtude, especialmente, da percepção de interação entre atores sociais mundiais, oportunidade em que fenômenos podem ser entendidos como interdependentes, não mais como isolados. Nesse aspecto, a ideia de rede permitiu arquitetar essa nova sociedade, considerando a possibilidade de interação, repulsão e programação de conteúdos nos fluxos informacionais. Nessa linha, o poder, também, pode ser visualizado de forma nodal, de modo a estudar o surgimento e competição de redes de poder dominantes e redes de contrapoder resistentes.

No segundo capítulo, estudou-se a formação de um sistema internacional de proteção à propriedade intelectual, predominantemente a fundação do regime de patentes, que concedem ao inventor de determinado objeto ou processo a garantia de monopólio sobre a exploração econômica daquele produto. Desenhou-se que esse 
sistema foi fortemente incentivado por uma economia capitalista mundial, encabeçado por países desenvolvidos, que, ao fim e ao cabo em 1994, com o surgimento da Organização Mundial do Comércio e com a assinatura do Acordo TRIPS, fortaleceram relações de dominância no mercado mundial, com a adoção de padrões mínimos de proteção e de subjugação à vontade de grandes corporações - indústrias farmacêuticas - e países desenvolvidos.

Por fim, no terceiro capítulo, visualizou-se que o atual sistema internacional de proteção à propriedade intelectual guarda inúmeros inconvenientes, que, nos termos de acesso a medicamentos, prejudica a população mais pobre de países em desenvolvimento ou menos desenvolvidos. Nesse ínterim, abordou-se os mecanismos existentes para flexibilizar as regras rígidas do Acordo TRIPS e permitir uma maior maleabilidade política para favorecer o acesso a medicamentos, fundamentalmente, a exaustão internacional de direitos ou importação paralela, o uso experimental ou exceção Bolar, a licença compulsória, a proibição de patentes de segundo uso e a participação do setor de saúde no processo de pedido de patente.

Nesse sentido, é possível perceber a existência de mecanismos capazes de contradizer e contraproduzir os enredos dominantes que prezam pela exploração econômica mundial de patentes de medicamentos em detrimento do direito fundamental à saúde, neste caso, perfectibilizado pelo acesso a remédios e tratamentos. Desse cotejo, e, respondendo ao problema do presente trabalho, nota-se que tais mecanismos de flexibilização do Acordo TRIPS podem ser entendidos e visualizados tais quais redes de contrapoder, arquitetadas para elaborar e reivindicar um projeto substitutivo de valores ignorados ou subjugados pelas redes de poder dominantes, argumentando que a Declaração de Doha sobre TRIPS e Saúde Pública, a Convenção sobre Diversidade Biológica e as parcerias firmadas pelo Sul Social são importantes escudos no jogo de poder da sociedade em rede.

Nota-se que o sistema internacional de proteção à propriedade intelectual é formado por diferentes atores e organizações sociais, inclusive por aquelas que pretendem introduzir novos ou, ainda, modificar velhos códigos na programação das redes de poder. Assim sendo, essas redes de contrapoder almejam, no jogo econômico mundial, a criação de novos protocolos de comunicação e fluxos de informações, seja a partir da reprogramação da rede de forma radical (licença compulsória, por exemplo), seja em seu conteúdo (interpretação sobre a possibilidade 
de patentear um segundo uso de medicamento, exemplificando), seja em sua expansão (com a formação de novas parcerias socioeconômicas, como, a título de exemplo, a união entre Brasil e Índia, no que tange a patente de medicamentos), seja a partir da competição entre redes (proposição de embargos econômicos no âmbito da Organização Mundial do Comércio para países que desrespeitam o Acordo TRIPS), seja a partir da cooperação entre redes (como, por exemplo, a instituição do paradigma da Declaração de Doha sobre TRIPS e Saúde Pública). 


\section{REFERÊNCIAS}

ARAUJO, Luiz Ernani Bonesso de. O Direito da Sociobiodiversidade. In: TYBUSCH, Jerônimo Siqueira; ARAUJO, Luiz Ernani Bonesso de; SILVA, Rosane Leal da (Orgs.). Direitos emergentes na sociedade global: anuário do programa de pós-graduação em direito da UFSM. Ijuí: Unijuí, 2013. pp. 269-291.

BRASIL. Decreto $n^{\circ} 1.355$ de 30 de dezembro de 1994. Promulgo a Ata Final que Incorpora os Resultados da Rodada Uruguai de Negociações Comerciais Multilaterais do GATT. Disponível em:

<http://www.planalto.gov.br/ccivil_03/decreto/antigos/d1355.htm>. Acesso em: 14 fev. 2019.

BRASIL. Decreto $n^{\circ} 2.519$, de 16 de março de 1998. Promulga a Convenção sobre Diversidade Biológica, assinada no Rio de Janeiro, em 05 de junho de 1992.

Disponível em: <http://www.planalto.gov.br/ccivil_03/decreto/d2519.htm>. Acesso em: 14 fev. 2019.

BRASIL. Decreto $n^{\circ} 75.699$, de 06 de maio de 1975. Promulga a Convenção de Berna para a Proteção das Obras Literárias e Artísticas, de 9 de setembro de 1886, revista em Paris, a 24 de julho de 1971. Disponível em:

<http://www.planalto.gov.br/ccivil_03/decreto/1970-1979/d75699.htm>. Acesso em: 14 fev. 2019.

BRASIL. Decreto $n^{\circ} 75.752$, de 08 de abril de 1975. Promulga a Convenção de Paris para a Proteção da Propriedade industrial revisão de Estocolmo, 1967. Disponível em: <http://www2.camara.leg.br/legin/fed/decret/1970-1979/decreto-75572-8-abril1975-424105-publicacaooriginal-1-pe.html>. Acesso em: 14 fev. 2019.

BRASIL. Lei no 9.279 , de 14 de maio de 1996. Regula direitos e obrigações relativos à propriedade industrial. Disponível em:

<http://www.planalto.gov.br/ccivil_03/Leis/L9279.htm>. Acesso em: 14 fev. 2019.

BRASIL. Ministério das Relações Exteriores. Acordo TRIPS. Disponível em:

<http://delbrasomc.itamaraty.gov.br/pt-br/acordo_trips.xml>. Acesso em: 21 fev. 2019.

BRASIL. Tribunal Regional Federal da $2^{\mathrm{a}}$ Região. Apelação Cível $\mathrm{n}^{\circ}$

2005.51.01.507811-1. Apelante: Instituto Nacional de Propriedade Industrial. Apelada: Eli Lilly and Company. Relator: Desembargador Federal Messod Azulay Neto. Rio de Janeiro, RS, 22 de setembro de 2009. Diário Oficial da União. Rio de Janeiro, 30 set. 
2009. Disponível em: <http://www.trf2.gov.br/cgi-bin/pingresallen? proc=200551015078111\&mov=1\&seqi=48>. Acesso em: 21 fev. 2019.

CAPRA, Fritjof. A teia da vida: uma nova compreensão científica dos sistemas vivos. Tradução de Newton Roberval Eichemberg. São Paulo: Cultrix, 1996.

CAPRA, Fritjof. As conexões ocultas. São Paulo: Cultrix, 2002.

CASTELLS, Manuel. A Era da Informação: economia, sociedade e cultura, vol. 3, São Paulo: Paz e Terra. 3. ed. 2002.

CASTELLS, Manuel. O poder da comunicação. São Paulo: Paz e Terra, 2016.

CHAVES, Gabriela Costa et al. A evolução do sistema internacional de propriedade intelectual: proteção patentária para o setor farmacêutico e acesso a medicamentos. Cadernos de Saúde Pública, Rio de Janeiro, v. 2, n. 23, p.257-267, fev. 2007. Disponível em:

<http://www.scielo.br/scielo.php?script=sci_arttext\&pid=S0102-311X2007000200002>. Acesso em: 17 fev. 2019.

COMUNIDADE DOS PAIISES DE LÍNGUA PORTUGUESA. Declaração sobre paz e desenvolvimento e o futuro da CPLP, de 01 de agosto de 2002. Disponível em: $<$ https://www.cplp.org/Admin/Public/DWSDownload.aspx?File=\%2fFiles\%2fFiler\%2fcpl p\%2fCCEG\%2flV_CCEG\%2fDECLARA\%ef\%bf\%bd\%ef\%bf\%bdOSOBREPAZDESEN VOLVIMENTO0EFUTURODACPLP.pdf>. Acesso em: 21 fev. 2019.

FOUCAULT, Michel. Microfísica do poder. 23. ed. São Paulo: Graal, 2004.

GALITO, Maria Sousa. Declaração de Doha. Disponível em: <http://www.cicpri.com/wp-content/uploads/2011/12/Declara\%C3\%A7ao-Doha3.pdf>. Acesso em: 21 fev. 2019.

LOVE, James Packard. Recent examples of the use of compulsory licenses on patentes: Knowledge Ecology International research note 2, de 31 de março de 2007. Disponível em: <https://www.keionline.org/misc-docs/recent_cls_8mar07.pdf>. Acesso em: 21 fev. 2019.

MENA, Fernanda. Cinco ultrarricos têm riqueza igual à metade do Brasil, aponta relatório. Disponível em: <http://www1.folha.uol.com.br/mercado/2018/01/1952267cinco-ultrarricos-tem-riqueza-igual-a-metade-do-brasil-aponta-relatorio.shtml>. Acesso em: 20 fev. 2019.

PINTO, Ana Paula Gomes. Patentes de segundo uso médico: Estudo sobre argumentos positivos e negativos para a concessão do registro no Brasil. In: Revista Jurídica da Presidência, Brasília, v. 14, n. 102, p.191-211, fev. 2012. Disponível em: $<$ https://revistajuridica.presidencia.gov.br/index.php/saj/article/viewFile/128/120>. Acesso em: 19 fev. 2019.

POGGE, Thomas. Medicamentos para o mundo: Incentivando a inovação sem obstruir o acesso livre. Sur. Revista Internacional de Direitos Humanos [online], v. 5, n. 8, 
p.123-149, jun. 2008. Disponível em: <http://www.scielo.br/pdf/sur/v5n8/v5n8a07.pdf>. Acesso em: 19 fev. 2019.

PRONER, Carol. Propriedade intelectual: para uma outra ordem jurídica possível. São Paulo: Cortez, 2007. Disponível em:

<http://bibliotecavirtual.clacso.org.ar/ar/libros/varios/Proner_2007.pdf>. Acesso em: 19 fev. 2019.

ROSINA, Mônica Steffen Guisé. A regulamentação internacional das patentes e sua contribuição para o processo de desenvolvimento do Brasil: análise da produção nacional de novos conhecimentos no setor farmacêutico. 2011. 247 f. Tese (Doutorado) - Curso de Direito, Universidade de São Paulo, São Paulo, 2011. Disponível em: <http://www.teses.usp.br/teses/disponiveis/2/2135/tde-15052012091832/publico/Monica_Steffen_Guise_Rosina_DO.pdf>. Acesso em: 15 fev. 2019.

ROSINA, Mônica Steffen Guisé. Comércio internacional, patentes e saúde pública. 2006. 137 f. Dissertação (Mestrado) - Curso de Direito, Universidade Federal de Santa Catarina, Florianópolis, 2007. Disponível em:

<http://www.dominiopublico.gov.br/download/teste/arqs/cp021315.pdf>. Acesso em: 15 fev. 2019.

SHIVA, Vandana. Monoculturas da mente: perspectivas da biodiversidade e biotecnologia. São Paulo: Gaia, 2002.

WIPO. Berne Convention for the Protection of Literary and Artistic Works.

Disponível em: <http://www.wipo.int/treaties/en/ip/berne/>. Acesso em: 15 fev. 2019a.

WIPO. Paris Convention for the Protection of Industrial Property, Disponível em: <http://www.wipo.int/treaties/en/ip/paris/>. Acesso em: 15 fev. $2019 \mathrm{~b}$.

WIPO. WIPO: A Brief History. Disponível em: <http://www.wipo.int/aboutwipo/en/history.html>. Acesso em: 15 fev. 2019c.

WTO. GATT members. Disponível em:

<https://www.wto.org/english/thewto_e/gattmem_e.htm>. Acesso em: 21 fev. 2019a.

WTO. Declaração de Doha sobre TRIPS e Saúde Pública, de 14 de novembro de 2001. Disponível em:

<http://www.wto.org/english/thewto_e/minist_e/min01_e/mindecl_trips_e.htm>. Acesso em: 21 fev. 2019b.

WTO. Trade-Related Aspects of Intellectual Property Rights. Disponível em: <https://www.wto.org/english/tratop_e/trips_e/trips_e.htm\#issues>. Acesso em: $21 \mathrm{fev}$. 2019c. 
Approved in 23/09/2019

Revista de Direitos Fundamentais \& Democracia, Curitiba, v. 26, n. 1, p. 6-29, jan./abr. 2021. 